\title{
Biological response of cancer cells to radiation treatment
}

\section{Rajamanickam Baskar*, Jiawen Dai, Nei Wenlong, Richard Yeo and Kheng-Wei Yeoh}

Division of Cellular and Molecular Research, Department of Radiation Oncology, National Cancer Centre, Singapore, Singapore

Edited by:

Maria Cecilia Giron, University of

Padova, Italy

\section{Reviewed by:}

Richard Chahwan, Albert Einstein

College of Medicine of Yeshiva

University, USA

Arun Bhardwaj, University of South

Alabama Mitchell Cancer

Institute, USA

Buck Rogers, Washington University

in St. Louis, USA

\section{${ }^{*}$ Correspondence:}

Rajamanickam Baskar, Molecular Radiobiology Laboratory, Division of Cellular and Molecular Research,

Department of Radiation Oncology, National Cancer Centre, 11- Hospital Drive, Singapore-169610, Singapore e-mail: r.baskar@nccs.com.sg
Cancer is a class of diseases characterized by uncontrolled cell growth and has the ability to spread or metastasize throughout the body. In recent years, remarkable progress has been made toward the understanding of proposed hallmarks of cancer development, care, and treatment modalities. Radiation therapy or radiotherapy is an important and integral component of cancer management, mostly conferring a survival benefit. Radiation therapy destroys cancer by depositing high-energy radiation on the cancer tissues. Over the years, radiation therapy has been driven by constant technological advances and approximately $50 \%$ of all patients with localized malignant tumors are treated with radiation at some point in the course of their disease. In radiation oncology, research and development in the last three decades has led to considerable improvement in our understanding of the differential responses of normal and cancer cells. The biological effectiveness of radiation depends on the linear energy transfer (LET), total dose, number of fractions and radiosensitivity of the targeted cells or tissues. Radiation can either directly or indirectly (by producing free radicals) damages the genome of the cell. This has been challenged in recent years by a newly identified phenomenon known as radiation induced bystander effect (RIBE). In RIBE, the non-irradiated cells adjacent to or located far from the irradiated cells/tissues demonstrate similar responses to that of the directly irradiated cells. Understanding the cancer cell responses during the fractions or after the course of irradiation will lead to improvements in therapeutic efficacy and potentially, benefitting a significant proportion of cancer patients. In this review, the clinical implications of radiation induced direct and bystander effects on the cancer cell are discussed.

Keywords: cancer cells, radiation, direct DNA damage, bystander effect

\section{INTRODUCTION}

Cancer is a complex disease, which grow locally and also possesses the capacity to metastasize to different organs in the body. Cancer continues to be a major disease and the numbers of cancer cases are projected to be more than double worldwide in the next 20-40 years and surpass heart disease as the leading cause of death (Jemal et al., 2010; Thun et al., 2010). Moreover, management of cancer is a rising concern in an aging population and is increasingly important in the developing countries (Siegel et al., 2012). International Agency for Research on Cancer (IARC) has predicted that by $2030, \sim 26$ million new cancer cases and 17 million cancer deaths will occur each year worldwide (IARC, 2010). That compares to 12.7 million new cancers and 7.6 million cancer death reported by GLOBOCAN 2008. Despite initial high response rates to the various treatment modalities and interventions, a large proportion of cancer patients suffered relapse in years or decades later (Karrison et al., 1999; Weckermann et al., 2001; Pfitzenmaier et al., 2006; Aguirre-Ghiso, 2007), resulting a therapeutic challenge. Radiation therapy aims to deliver the optimal isodose to the tumor volume while sparing the normal tissues. For years, radiation biologists have thought that the biological effects induced by ionizing radiation are the direct consequence of a radiation induced DNA damage and thereafter death of cancer cell. In a recent seminal study Martin et al. (2014) reported that the rapid breakdown of a tumor could cause a flood of cancerous material, including intact cells to enter the lymphatic flow and form tumors in the distanced organs, a possible mechanism of the formation of therapy related metastasis. Therefore, past 20 years have seen a major paradigm shift in radiation biology and enormous progress has been made to understand the biological and molecular determinants of cellular radiation responses.

In recent years, many treatment and management options for cancer exist with the primary ones including: surgery, chemotherapy, radiation therapy and palliative care. Radiation therapy or radiotherapy is a highly effective tool for the cancer treatment and also an important component of cancer management, conferring a survival and palliative benefits (Prise, 2006; Guadagnolo et al., 2013; Liauw et al., 2013). In patients with inoperable tumors, radiation therapy is the only option (Durante and Loeffler, 2010). Furthermore, patients who are incompletely resected or recurrent of tumors after surgery are mostly treated by radiation therapy (Durante and Loeffler, 2010). Approximately 50\% of all cancer patients receive radiation therapy during their course of illness (Delaney et al., 2005; Begg et al., 2011) either for cure or as a palliative treatment to relieve the patients from symptoms such as pain caused by the cancer (Delaney et al., 2005), majority of patients are treated with the intent to cure (Barnett et al., 2009). Although tremendous progress has been made toward understanding the hallmarks of cancer development and treatment 
response, a need remains to improve the curative rate by targeting multiple molecular pathways that mediate the DNA damage response.

Radiation therapy destroys cancer by depositing high physical energy of radiations on the cancer cells. The first clinical use of radiation for the cancer treatment was recorded in late 19th century (Connell and Hellman, 2009), soon after Roentgen discovered X-rays in 1895 and the effectiveness of radiation that has been developed over the years showed a drastic beneficial effects (Bernier et al., 2004; Giap and Giap, 2012). Over the years, radiation therapy has been driven by constant technological advances (Thariat et al., 2013) with the understanding of various molecular mechanisms involved in the treatment sensitivity and resistance (Jacinto and Hall, 2003; Camphausen and Tofilon, 2004; Sabatini, 2006; Kuwahara et al., 2014). In radiation oncology, research and development in the last three decades has led to a considerable improvement in our understanding of radiation dose and the dose-volume responses. Ionizing radiation has been harnessed for over a century to treat patients with cancer largely based on the rationale that the rapidly proliferating cancer cells are more sensitive than normal cells for the DNA damage response. Recently, our understanding of radiation effects has been expanded widely in terms of the consequences of radiation-induced tumor cell death and various signaling pathways involved in sensitivity, resistance and further molecular sensors that modify the tumor response to radiation. Though high-energy photons (X-rays and gamma rays) are the most common radiation modalities used in the external beam treatment, protons provide dosimetric advantages compared with photons. In this review, we discuss about the biological response of rapidly proliferating cancer cells to the radiation treatment.

\section{RADIATION AND BIOLOGICAL IMPLICATIONS}

Radiation remains as most widely utilized treatment modalities in the clinical management of cancer (Burnette and Weichselbaum, 2013; McGale et al., 2014). Patients with localized malignant tumors are treated with radiation at some point in the course of their disease (Bentzen, 2006; Durante and Loeffler, 2010; Baskar et al., 2012; Moding et al., 2013). Radiation therapy is applied in a course of multiple fractions over several weeks to reduce the normal cell toxicity (Bentzen, 2006), with an estimation of about $40 \%$ toward the curative treatment (Barnett et al., 2009). Furthermore, radiation therapy is a highly cost effective with a single modality treatment accounting about only $5 \%$ of the total cost of cancer care (Ringborg et al., 2003). Therefore, any improvement in the efficacy of radiation therapy will therefore benefit a large number of patients. Recent advances in radiation therapy have enabled the use of different types of radiation sources like photons and protons for a better cancer treatment efficacy. Radiation therapy uses low and high linear energy transfer (LET) radiations to efficiently kill the tumor cells while minimizing dose (biological effective) to normal tissues to prevent toxicity (Lawrence et al., 2008; Niemantsverdriet et al., 2012). LET is defined as measurement of the number of ionizations which radiation causes per unit distance as it traverses the living cells or tissue. X-rays, gamma rays and charged particles are the most types of radiation used for cancer treatment. In radiation oncology, radiations can be delivered by a machine outside the body (external beam radiation therapy) or irradiated through the radioactive material placed in the body near to cancer cells/tissue (internal radiation therapy, also called brachytherapy). On the other hand, systemic radiation therapy uses radioactive substances, such as radioactive iodine, that travel in the blood to kill the cancer cells.

A better understanding of biological effects of radiation will lead to efficient use and better protection. Biological effectiveness of radiation depends on the linear energy transfer (LET), total dose, fractionation rate and radiosensitivity of the targeted cells or tissues (Hall, 2007). Low LET radiations (X-rays, gamma rays and beta particles) deposit a relatively small quantity of energy. On the other hand, radiation particles either negatively charged (electrons), positively charged (protons, alpha rays, and other heavy ions) deposits more energy on the targeted areas called the Bragg peak and causes more biological effects than the low LET radiations. However, tumors have developed multiple strategies to resist radiation damage. The following (1) Tumor burden (2) Tumor microenvironment/hypoxia (3) Inherent or acquired treatment resistance and (4) Repopulations during the treatment are the major mechanisms involved in the treatment resistance (Seiwert et al., 2007). Ionizing radiation effectively kills human cells; over a period sufficiently high doses of radiation can sterilize any tumor and achieve nearly $100 \%$ of tumor control probability (TCP) (Thariat et al., 2013), either alone or in combination with surgery and chemotherapy. However, when using external-beam radiation healthy tissues are unavoidably exposed to radiation, which increases the normal tissue complication probability. Over the years, technological improvements in radiation therapy delivery have aimed to widen the therapeutic window while reducing the normal tissue impact and increase in target tissue (tumor) control (Durante and Loeffler, 2010; Loeffler and Durante, 2013), and the benefits will be three-fold: patient cure, organ preservation and cost-efficiency.

The overall outcome of radiation treatment is cell or tissue damage; if it is not repairable eventually kill the cells. Effectiveness of radiation therapy that have been developed over years showed an increase in the number of cancer survivors, but preventing or reducing late effects are a significant public health issue. Furthermore, increase in the number of cancer survivors has stimulated interest in the quality of life of cancer survivors. The situation is important among non-elderly adults. In particular, children are inherently more radiosensitive and have more remaining years of life during which radiation induced late effect in normal cells could manifest in their hyperproliferation (Allan and Travis, 2005). However, understanding the tumor biology and considerable technical advancement (e.g., proton therapy) over the last three decades provides the opportunity for better cancer treatment.

\section{DIRECT EFFECTS}

Ionizing radiation has been used for more than a century to treat the cancer based on the rationale that the rapidly proliferating cancer cells are sensitive to the radiation treatment than normal cells (Bernier et al., 2004). Under the target-cell damage, the major effect of ionizing radiation on tissues are the direct cell killing mostly by damaging the DNA, resulting in the 
depopulation of cell populations and subsequent functional deficiency. Radiation induced ionizations can act directly on the cellular molecules and cause damage (Figure 1). Also can act indirectly, producing free radicals which are derived from the ionization or excitation of the water component $(80 \%$ of a cell is composed of water) of the cells (Figure 1). For ionizing radiations such as low LET X-rays and gamma-rays, 60\% of cellular damage is caused by the indirect effects (Barcellos-Hoff et al., 2005). Radiation induced double strand breaks (DSBs) represent the most lethal types of DNA damage, leading to cell death, if unrepaired. However, DNA damage response mechanisms represent a vital line of defense against exogenous and endogenous damage caused by radiation and promote two distinct outcomes: survival and the maintenance of genomic stability.

Multiple pathways are involved in the genome maintenance of a cell after its exposure to ionizing radiation. Radiation therapy like the most anticancer treatments achieves its therapeutic effect by inducing DNA damage and thereafter cell death (Baskar et al., 2008). Several experiments were performed indicating that the DNA of cancer cells repair more slowly and also produce more DNA breaks (single strand break and double strand breaks) than the normal cells (Parshad et al., 1993; Shahidi et al., 2007, 2010; Mohseni-Meybodi et al., 2009). Furthermore, various proteins involved in cell death and DNA damage mechanisms (Jorgensen, 2009) decrease the radioresistance of the fast doubling cancer cells, while increase in radioresistance of slow doubling normal cells (Figure 2). Therefore, ionizing radiation as applied in the cancer treatment induces a complex response in the cells. Some processes aim to repair the radiation induced damage of the normal cells, whereas others counteract the damage or induce cancer cell death. Growing evidence suggests that various signaling pathways including the DNA repair response pathways shows redundancy in normal cells (Moding et al., 2013). Since cancer cells have various mutations that cause the loss of this redundancy and therefore targeting the DNA damage response pathways in the

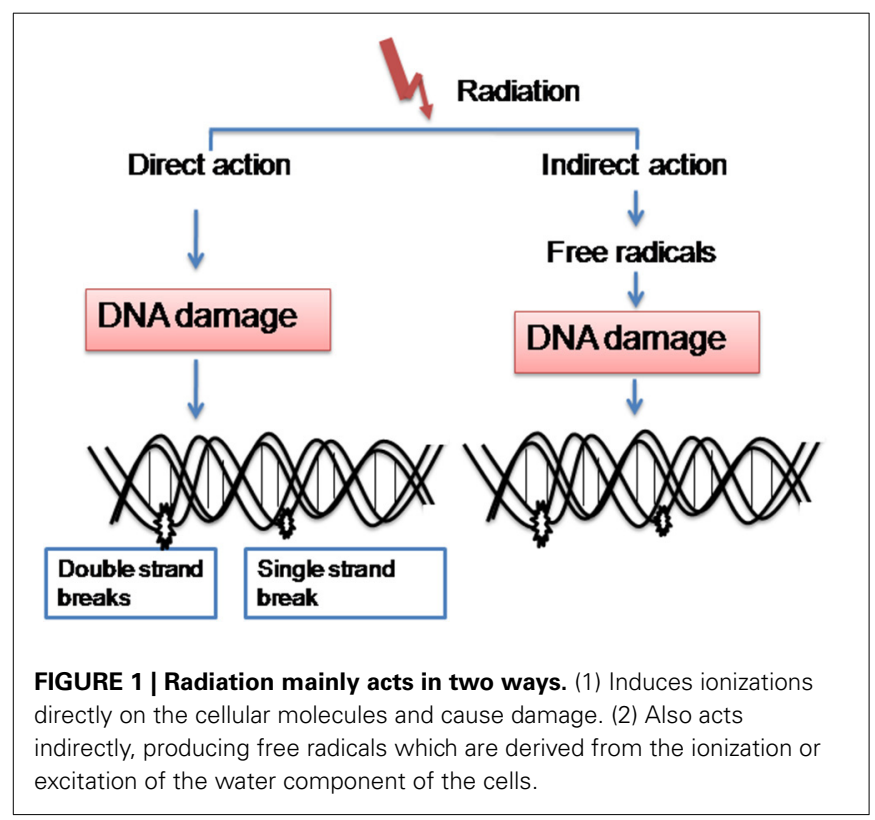

cancer cells can induce cell death. Hence DNA is the main target for radiation-induced cell killing (Jorgensen, 2009) and there is considerable redundancy in the ability of normal cells to repair DNA damage (Núñez et al., 1996), therefore targeting DNA damage response pathways is a promising approach for the selective radiosensitization of cancer cells (Helleday et al., 2008).

p53 is a transcription factor and also one of the most commonly mutated genes in cancer (Brosh and Rotter, 2009) responds to ionizing radiation by initiating cell cycle arrest, senescence, apoptosis and DNA damage repair (Stiewe, 2007). However, whether p53 induces apoptosis or cell cycle arrest for the DNA damage repair is a complex process and partly depends on the abundance of the $\mathrm{p} 53$ protein (low protein levels lead to cell cycle arrest and high protein levels lead to apoptosis) (Lai et al., 2007). However, various DNA repair mechanisms within the tumor cells interfere with the radiation induced damage and further increase the radioresistance of cancer cells (Jorgensen, 2009). Furthermore, inhibition of DNA repair proteins such as ATM or DNA-dependent protein kinase (DNA-PK) have been shown to sensitize the cancer cells to radiation treatment (Veuger et al., 2003; Hickson et al., 2004; Rainey et al., 2008).

Besides the DNA repair pathways, ionizing radiation also triggers cancer cells adaptive cellular responses. Various treatment resistant signal transduction pathways are activated and the resistance can be either intrinsic or an acquired resistance during the fractionated radiation treatment (Toulany and Rodemann, 2013). Signaling pathways that provide cancer cells with a proliferative advantage or allow them to evade the cell death remains a major clinical problem. One of the molecular events by which tumors can become radioresistant is through the ligand-independent activation of signal transduction pathways such as those regulated by membrane-bound receptor tyrosine kinases (RTKs). In this context, epidermal growth factor receptor (EGFR) plays a major role in regulating various downstream signaling pathways, such as the phosphatidylinositol 3-kinase (PI3K) and its downstream kinases such as AKT and mammalian target of rapamycin (mTOR), signal transducer and activator of transcription (STAT) pathway and Ras-mitogen-activated protein kinase (MAPK) pathway (Rodemann et al., 2007; Rodemann and Blaese, 2007). These pathways control the most hallmarks of cancer, including cell cycle, survival, metabolism, invasion, angiogenesis, and genomic instability (Datta et al., 1997; Huang and Harari, 2000; Nyati et al., 2006). Among the prosurvival pathways activated by RTKs, PI3K-AKT-mTOR signaling pathway is frequently upregulated in human tumors and regarded as one of the most challenging prosurvival pathways involved in the resistance to cancer treatment (Engelman, 2009; Liu et al., 2010; Castellano and Downward, 2011).

Recent advances in cancer biology have demonstrated that PI3K-AKT-mTOR signaling pathway controls Fanconi anemia group D2 protein (FANCD2) and ribonucleotide reductase (RNR) and further prolongation of radiation-induced gamma H2AX foci formation (Choi et al., 2010; Shen et al., 2013; Wang et al., 2014). Regulation of DNA repair genes (FANCD2 and RNR) suggests that the PI3K-AKT-mTOR signaling promotes cancer cell survival and resistance to radiation treatment 


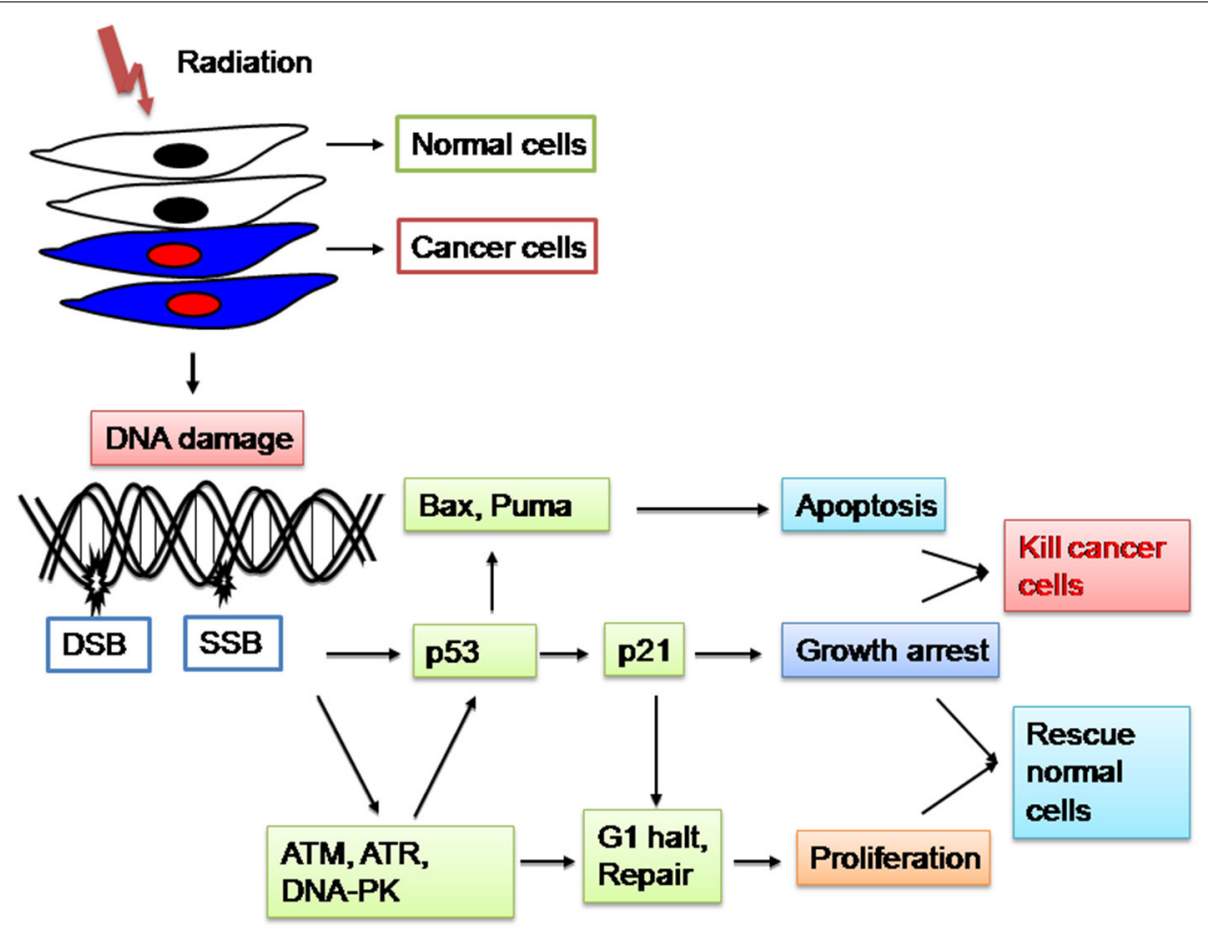

FIGURE 2 | Radiation damages the genetic material (DNA) causing single strand breaks (SSB) or double strand breaks (DSB) in the cells, thus blocking their ability to divide and proliferate further. Mechanisms involved in the decrease of radiosensitivity of the fast doubling cancer cells, while increasing radioresistant of the slow doubling normal cells benefits the cancer patients. by enhancing the DNA damage repair of the cancer cells. In addition, PI3K-AKT-mTOR signaling pathway also may play a role in the integral functions for non-cancerous (normal) cells repopulation along with the proteins involved in DNA repair mechanisms (Wullschleger et al., 2006). Ionizing radiation also activates NF- $\kappa \mathrm{B}$ transcriptional pathway, through the activation of I $\mathrm{B}$ kinase- $\alpha$ as a protective response to damage and inhibition of this kinase can lead to increased radiosensitvity for the cancer treatment (Brach et al., 1991; Criswell et al., 2003). However, how these pathways inhibition may improve the radiation therapy efficacy in patients remains elusive and the mechanisms underlying the initiation/manifestation of radiation-induced genomic instability in normal and cancer cells are far understood (Bensimon et al., 2013). Furthermore, improvement in preclinical methods for the biological mechanisms involved in signaling pathway(s) for the treatment resistance, cell cycle checkpoints, DNA damage and repair, anti-angiogenesis could increase the therapeutic response of tumor microenvironment, while sparing the surrounding normal tissues. As a result, inhibition of the cancer cells prosurvival pathways has the potential to increase the radiosensitivity of cancer cells through activating/inhibiting multiple mechanisms. Furthermore, inhibition of the cancer cell survival could also affect the radiosensitivity of normal tissues as well, thus decreasing the overall therapeutic index of radiation. Therefore, strategies to improve radiation therapy to increase the effect on tumor while less toxicity on the normal tissues should be achieved without sensitizing the normal tissues and also without protecting the tumors to the radiation treatment.

\section{BYSTANDER EFFECTS}

Cancer therapy usually involves exposing the body to agents that kill cancer cells more efficiently than the normal cells. Recent advances in radiation biology and oncology have demonstrated that the radiation is an effective tool to control the localized tumors. However, in recent years mounting evidence indicates that the radiation also can damage not only the cells adjacent to the tumor, but also far from the radiation track by the generation of gap-junction or cytokine-mediated cellular toxicity and also various cellular and microenvironmental signaling cascades are involved (Figure 3) (Shao et al., 2004; BarcellosHoff et al., 2005; Baskar, 2010; Butterworth et al., 2013; Suzuki and Yamashita, 2014). In the past two decades, evidence has been mounted for a novel biological phenomenon termed as "bystander effect" (BE). Ionizing radiation induces DNA damage in the form chromosomal aberrations were first reported not only in the directly exposed cells but also in their neighboring non-irradiated cells, termed as radiation-induced bystander effect (RIBE) (Nagasawa and Little, 1992). Therefore, the discovery of non-targeted responses to radiation, such as the bystander response, has called the direct radiation effect paradigm into question. Various biological effects of ionizing radiation are not restricted to only the directly irradiated cells (targeted effects), but are also observed in the progeny of non-irradiated cells (non-targeted effects) (Bensimon et al., 2013). RIBE has been demonstrated in numerous in vitro and in vivo studies using a variety of biological endpoints. These effects include various molecular and genomic instabilities as seen in the targeted cells. 


\section{Irradiated cell}

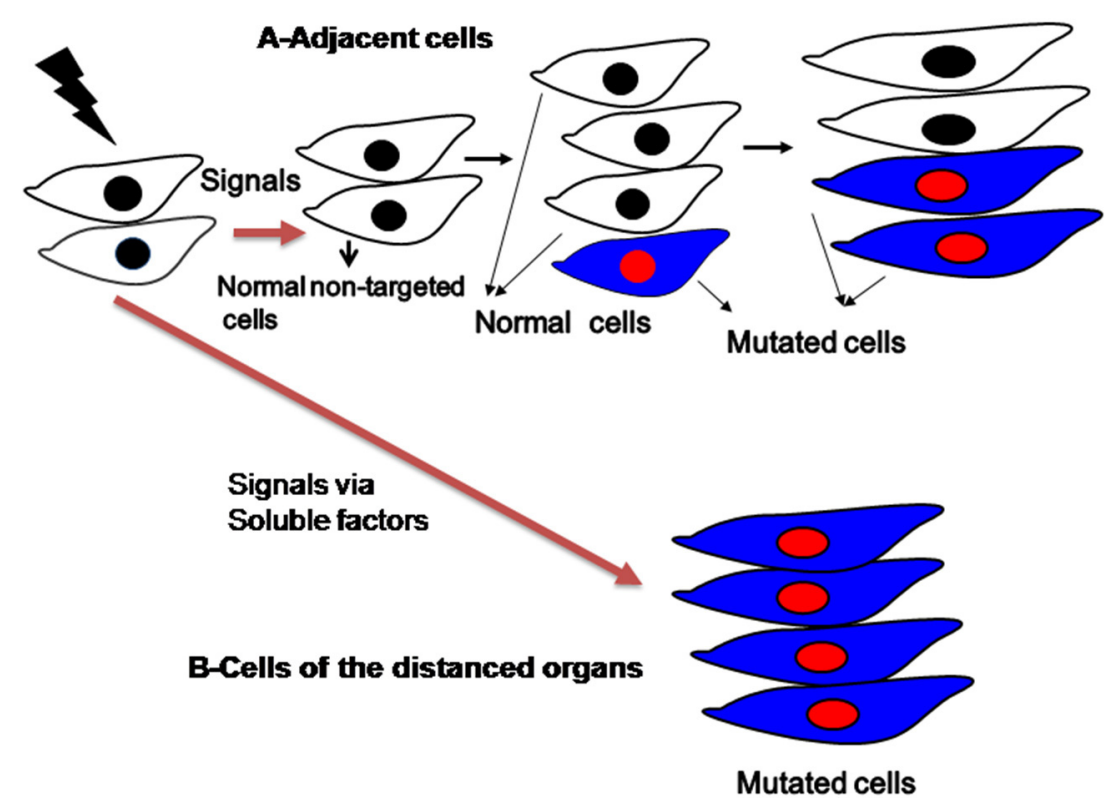

FIGURE 3 | Schematic representation of bystander effects induced by radiation to the adjacent cells and distanced organs.

Bystander effects has been extensively studied in the past two decades and reported cell death (Seymour and Mothersill, 1997), induction of sister chromatid exchanges (Nagasawa and Little, 1992; Deshpande et al., 1996), formation of micronuclei (Shao et al., 2003; Balajee et al., 2004; Ponnaiya et al., 2004), mutations (Zhou et al., 2000), delay in cell cycle (Ponnaiya et al., 2004) and transformation (Sawant et al., 2001) of non-irradiated cells along with the proteins involved in the cell cycle and DNA damage response (Hickman et al., 1994; Azzam et al., 1998, 2001; Sokolov et al., 2007; Baskar et al., 2008).

Radiation can cause chromosomal aberrations arising de novo in the cell progeny, several generations after irradiation. Delayed genomic instability has been observed in many types of mammalian cells (Ponnaiya et al., 1997; Suzuki et al., 2003; Mothersill et al., 2006; Sudo et al., 2008). Therefore, communication between cells and their microenvironment is critical for both normal tissue homeostasis and tumor growth. RIBE has important implication in tumor control and in radiation therapy, wherein the targeted (directly irradiated) cells transmit the damaging signals to the non-irradiated normal cells, thereby inducing a response similar to that of directly irradiated cells (Mothersill and Seymour, 1998; Shao et al., 2002; Baskar et al., 2007; Baskar, 2010; He et al., 2012). Two major mechanisms mediate RIBE. In the normal and certain cancer cells, mechanisms between cell to cell communications are through the direct gap junctionmediated intercellular communication (adjacent cells/confluent cells) (Azzam et al., 1998; Zhou et al., 2000). Secondly, a range of soluble signaling molecules such as cytokines are involved in the communications between the targeted to distanced nontargeted organs/sub-confluent cells were reported (Ivanov et al., 2010; Hei et al., 2011; Klammer et al., 2013). Among cytokines, tumor growth factor-beta-1 (TGF- $\beta 1$ ) has been found to be an important mediator in the bystander effects (Gow et al., 2010; Temme and Bauer, 2013). Recently, Jiang et al. (2014) showed in the lung cancer cells, that the RIBE is mediated by the TGF- $\beta 1-$ miR-21-ROS pathway. In recent years, number of candidate mediators in bystander effects were identified, among them transforming growth factor-b (TGF- $\beta$ ) (Iyer et al., 2000), tumor necrosis factor-alpha (a) (TNF- $\alpha$ ) (Shareef et al., 2007), interleukin-6 (IL-6) (Chou et al., 2007), interleukin-8 (IL-8) (Facoetti et al., 2006) and increase in reactive oxygen species (ROS) (Lyng et al., 2002). RIBE has an important implication in radiation therapy and its impact in radiation oncology is gradually beginning (Munro, 2009). In cancer cells multiple RIBEs, including cell growth stimulation, DNA damage, and cell death have been observed (Sokolov and Neumann, 2010; Veldwijk et al., 2014). However, RIBE is not seen in the human embryonic stem cells (hESC) (Sokolov and Neumann, 2010), indicating stem cells are less susceptible to RIBE than the somatic differentiated cells.

RIBE is also reported using mouse model, the bystander responses of internal tumor cells or tissues were also confirmed in vivo, further cancer-associated events such as p53 alteration, MMPs (Matrix metalloproteinases) activity and epigenetic changes were reported in the RIBE (Camphausen et al., 2003; Koturbash et al., 2007). BE can be mediated through an increase in genomic instability, cell cycle delay, cell death (apoptosis), formation of micronucleus, mutations, changes in proteins (gene) expression, and further by malignant transformation (Nagasawa and Little, 1992; Hickman et al., 1994; Shao et al., 2003; Ponnaiya et al., 2004; Baskar et al., 2008). However, the components released from the irradiated cells and further the communication signals involved between the irradiated and non-irradiated 
cells are still not well known. Recently, Bensimon et al. (2013) showed for the first time in breast cancer cells, a cancer stem cell (CSC) marker CD24 is associated with the transmission of genomic instability of the bystander cells. Recently Aravindan et al. (2014) reported that the clinical doses of abdominal irradiation (2Gy) in mice showed an increase in the onset of NF-kB signal transduction and subsequent NF-kB activation in the nontargeted distant organ (heart). However, little is known about the type of DNA damage of the bystander cells, its radiation resistance and further damage of non-targeted normal cells contributing to tumorigenesis and how this damage can be repaired by designing novel therapeutic approaches to cancer treatment paves a way for an effective strategy to compact the disease.

\section{FUTURE PERSPECTIVE}

Though tremendous progress has been made toward understanding the hallmarks of cancer, cancer is responsible for one in eight deaths worldwide (Garcia et al., 2007; Center et al., 2011). Despite the use of chemotherapy, radiation therapy and surgery, the overall outcome for cancer cure continues to be disappointing. Radiation therapy offers an effective treatment for advanced cancer and the prime goal of radiation treatment is to inhibit the cancer cells multiplication potential and eventually kill the cells. However, radioresistance and repopulation (relapse or recurrence) at the primary site and/or at the malignant areas remain a significant clinical challenge in cancer control. Certain tumors are intrinsically radioresistant, while others acquire radioresistance during the treatment (Seiwert et al., 2007). To overcome the tumor cell radioresistance, it will be a challenging one to identify tumor specific pathways and inhibitors. In the past few years, enormous progress has been made in radiation therapy leading to the possibility of depositing more radiation energy (proton beam radiation therapy, e.g., Bragg Peak) on the tumors while sparing the surrounding normal tissues (Bhide and Nutting, 2010). We do not have a comprehensive answer about the molecular mechanisms involved in the initiation of cancer, developing resistance to treatment and further individual variations in treatment susceptibility, especially of therapy-related beneficial or detrimental effects. In a microenvironment, cancer cells are influenced by various growth signaling pathways to resist the radiation effects and further modify the adjacent normal tissues to impede tumor recurrence or metastasis. Overall, small increase in radioresistance will lead to a large number of cancer cell survivals and further the proliferation forms cancer mass and with a logarithmic decrease in cancer cell death after radiation treatment. Therefore, in the coming years more thrust should be given on the cancer cells radioresistance, e.g., cancer stem cell's radiosensitivity will focus on several different areas along with molecular targeted drugs to control this rapidly growing disease worldwide. Furthermore, with a greater understanding of the tumor biology, evolution of radiation therapy will continue with the improvements in imaging, computing and engineering advancements, and potentially decimate the cancer cells with fewer side effects.

\section{ACKNOWLEDGMENTS}

This work was supported by the National Medical Research Council (BNIG11nov004) Singapore to Rajamanickam Baskar.
I am indebted to Dr. Kothandharaman Subramanian for his critical editorial comments and help in the preparation of this manuscript.

\section{REFERENCES}

Aguirre-Ghiso, J. A. (2007). Models, mechanisms and clinical evidence for cancer dormancy. Nat. Rev. Cancer 7, 834-846. doi: 10.1038/nrc2256

Allan, J. M., and Travis, L. B. (2005). Mechanisms of therapy-related carcinogenesis. Nat. Rev. Cancer 5, 943-955. doi: 10.1038/nrc1749

Aravindan, N., Aravindan, S., Pandian, V., Khan, F. H., Ramraj, S. K., Natt, P., et al. (2014). Acquired tumor cell radiation resistance at the treatment site is mediated through radiation-orchestrated intercellular communication. Int. J. Radiat. Oncol. Biol. Phys. 88, 677-685. doi: 10.1016/j.ijrobp.2013.11.215

Azzam, E. I., de Toledo, S. M., Gooding, T., and Little, J. B. (1998). Intercellular communication is involved in the bystander regulation of gene expression in human cells exposed to very low fluences of alpha particles. Radiat. Res. 150, 497-504. doi: 10.2307/3579865

Azzam, E. I., de Toledo, S. M., and Little, J. B. (2001). Direct evidence for the participation of gap junction-mediated intercellular communication in the transmission of damage signals from alpha -particle irradiated to nonirradiated cells. Proc. Natl. Acad. Sci. U.S.A. 98, 473-478. doi: 10.1073/pnas.98.2.473

Balajee, A. S., Ponnaiya, B., Baskar, R., and Geard, C. R. (2004). Induction of replication protein A in bystander cells. Radiat. Res. 162, 677-686. doi: 10.1667/RR3269

Barcellos-Hoff, M. H., Park, C., and Wright, E. G. (2005). Radiation and the microenvironment-tumorigenesis and therapy. Nat. Rev. Cancer 5, 867-875. doi: $10.1038 / \mathrm{nrcl} 1735$

Barnett, G. C., West, C. M. L., Dunning, A. M., Elliott, R. M., Coles, C. E., Pharoah, P. D. P., et al. (2009). Normal tissue reactions to radiotherapy: towards tailoring treatment dose by genotype. Nat. Rev. Cancer 9, 134-142. doi: 10.1038/ nrc2587

Baskar, R., Balajee, A. S., and Geard, C. R. (2007). Effects of low and high LET radiations on bystander human lung fibroblast cell survival. Int. J. Radiat. Biol. 83, 551-559. doi: 10.1080/09553000701384499

Baskar, R., Balajee, A. S., Geard, C. R., and Hande, M. P. (2008). Isoformspecific activation of protein kinase $\mathrm{c}$ in irradiated human fibroblasts and their bystander cells. Int. J. Biochem. Cell. Biol. 40, 125-134. doi: 10.1016/j.biocel.2007.07.002

Baskar, R. (2010). Emerging role of radiation induced bystander effects: cell communications and carcinogenesis. Genome Integr. 1:13. doi: 10.1186/20419414-1-13

Baskar, R., Lee, K. A., Yeo, R., and Yeoh, K.-W. (2012). Cancer and radiation therapy: current advances and future directions. Int. J. Med. Sci. 9, 193-199. doi: 10.7150/ijms.3635

Begg, A. C., Stewart, F. A., and Vens, C. (2011). Strategies to improve radiotherapy with targeted drugs. Nat. Rev. Cancer 11, 239-253. doi: 10.1038/nrc3007

Bensimon, J., Altmeyer-Morel, S., Benjelloun, H., Chevillard, S., and Lebeau, J. (2013). CD24(-/low) stem-like breast cancer marker defines the radiationresistant cells involved in memorization and transmission of radiation-induced genomic instability. Oncogene 32, 251-258. doi: 10.1038/onc.2012.31

Bentzen, S. M. (2006). Preventing or reducing late side effects of radiation therapy: radiobiology meets molecular pathology. Nat. Rev. Cancer 6, 702-713. doi: $10.1038 / \mathrm{nrc1} 950$

Bernier, J., Hall, E. J., and Giaccia, A. (2004). Radiation oncology: a century of achievements. Nat. Rev. Cancer 4, 737-747. doi: 10.1038/nrc1451

Bhide, S. A., and Nutting, C. M. (2010). Recent advances in radiotherapy. BMC Med. 8:25. doi: 10.1186/1741-7015-8-25

Brach, M. A., Hass, R., Sherman, M. L., Gunji, H., Weichselbaum, R., and Kufe, D. (1991). Ionizing radiation induces expression and binding activity of the nuclear factor kappa B. J. Clin. Invest. 88, 691-695. doi: 10.1172/JCI115354

Brosh, R., and Rotter, V. (2009). When mutants gain new powers: news from the mutant p53 field. Nat. Rev. Cancer 9, 701-713. doi: 10.1038/nrc2693

Burnette, B., and Weichselbaum, R. R. (2013). Radiation as an immune modulator. Semin. Radiat. Oncol. 23, 273-280. doi: 10.1016/j.semradonc.2013.05.009

Butterworth, K. T., McMahon, S. J., Hounsell, A. R., O’Sullivan, J. M., and Prise, K. M. (2013). Bystander signalling: exploring clinical relevance through new approaches and new models. Clin. Oncol. (R. Coll. Radiol.). 25, 586-592. doi: 10.1016/j.clon.2013.06.005 
Camphausen, K., Moses, M. A., Ménard, C., Sproull, M., Beecken, W.-D., Folkman, J., et al. (2003). Radiation abscopal antitumor effect is mediated through p53. Cancer Res. 63, 1990-1993. doi: 10.1016/S0360-3016(02)03449-1

Camphausen, K., and Tofilon, P. J. (2004). Combining radiation and molecular targeting in cancer therapy. Cancer Biol. Ther. 3, 247-250. doi: 10.4161/cbt.3.3.544

Castellano, E., and Downward, J. (2011). RAS interaction with PI3K: more than just another effector pathway. Genes Cancer 2, 261-274. doi: $10.1177 / 1947601911408079$

Center, M., Siegel, R., and Jemal, A. (2011). American Cancer Society. Global Cancer Facts and Figures, 2nd Edn. Atlanta, GA: American Cancer Society, 1-58.

Choi, E. J., Ryu, Y. K., Kim, S. Y., Wu, H. G., Kim, J. S., Kim, I. H., et al. (2010). Targeting epidermal growth factor receptor-associated signaling pathways in non-small cell lung cancer cells: implication in radiation response. Mol. Cancer Res. 8, 1027-1236. doi: 10.1158/1541-7786.MCR-09-0507

Chou, C. H., Chen, P.-J., Lee, P.-H., Cheng, A.-L., Hsu, H.-C., and Cheng, J. C.-H. (2007). Radiation-induced hepatitis B virus reactivation in liver mediated by the bystander effect from irradiated endothelial cells. Clin. Cancer Res. 13, 851-857. doi: 10.1158/1078-0432.CCR-06-2459

Connell, P. P., and Hellman, S. (2009). Advances in radiotherapy and implications for the next century: a historical perspective. Cancer Res. 69, 383-392. doi: 10.1158/0008-5472.CAN-07-6871

Criswell, T., Leskov, K., Miyamoto, S., Luo, G., and Boothman, D. A. (2003). Transcription factors activated in mammalian cells after clinically relevant doses of ionizing radiation. Oncogene 22, 5813-5827. doi: 10.1038/sj.onc.1206680

Datta, S. R., Dudek, H., Tao, X., Masters, S., Fu, H., Gotoh, Y., et al. (1997). Akt phosphorylation of BAD couples survival signals to the cell-intrinsic death machinery. Cell 91, 231-241. doi: 10.1016/S0092-8674(00)80405-5

Delaney, G., Jacob, S., Featherstone, C., and Barton, M. (2005). The role of radiotherapy in cancer treatment: estimating optimal utilization from a review of evidence-based clinical guidelines. Cancer 104, 1129-1137. doi: $10.1002 /$ cncr. 21324

Deshpande, A., Goodwin, E. H., Bailey, S. M., Marrone, B. L., and Lehnert, B. E. (1996). Alpha-particle-induced sister chromatid exchange in normal human lung fibroblasts: evidence for an extranuclear target. Radiat. Res. 145, 260-267. doi: $10.2307 / 3578980$

Durante, M., and Loeffler, J. S. (2010). Charged particles in radiation oncology. Nat. Rev. Clin. Oncol. 7, 37-43. doi: 10.1038/nrclinonc.2009.183

Engelman, J. A. (2009). Targeting PI3K signalling in cancer: opportunities, challenges and limitations. Nat. Rev. Cancer 9, 550-562. doi: 10.1038/nrc2664

Facoetti, A., Ballarini, F., Cherubini, R., Gerardi, S., Nano, R., Ottolenghi, A., et al. (2006). Gamma ray-induced bystander effect in tumour glioblastoma cells: a specific study on cell survival, cytokine release and cytokine receptors. Radiat. Prot. Dosimetry 122, 271-274. doi: 10.1093/rpd/ncl431

Garcia, M., Jemal, A., Ward, E. M., Center, M. M., Hao, Y., Siegel, R. L., et al. (2007). Global Cancer Facts and Figures. Atlanta, GA: American Cancer Society, 1-50.

Giap, H., and Giap, B. (2012). Historical perspective and evolution of charged particle beam therapy. Transl. Cancer Res. 1, 127-136. doi: 10.3978/j.issn.2218676X.2012.10.09

Gow, M. D., Seymour, C. B., Ryan, L. A., and Mothersill, C. E. (2010). Induction of bystander response in human glioma cells using high-energy electrons: a role for TGF-beta1. Radiat. Res. 173, 769-778. doi: 10.1667/RR1895.1

Guadagnolo, B. A., Liao, K.-P., Elting, L., Giordano, S., Buchholz, T. A., and Shih, Y.-C. T. (2013). Use of radiation therapy in the last 30 days of life among a large population-based cohort of elderly patients in the United States. J. Clin. Oncol. 31, 80-87. doi: 10.1200/JCO.2012.45.0585

Hall, E. J. (2007). Cancer caused by x-rays-a random event? Lancet Oncol. 8, 369-370. doi: 10.1016/S1470-2045(07)70113-4

He, M., Ye, S., Ren, R., Dong, C., Xie, Y., Yuan, D., et al. (2012). Cytochrome-c mediated a bystander response dependent on inducible nitric oxide synthase in irradiated hepatoma cells. Br. J. Cancer 106, 889-895. doi: 10.1038/bjc.2012.9

Hei, T. K., Zhou, H., Chai, Y., Ponnaiya, B., and Ivanov, V. N. (2011). Radiation induced non-targeted response: mechanism and potential clinical implications. Curr. Mol. Pharmacol. 4, 96-105. doi: 10.2174/18744667211104020096

Helleday, T., Petermann, E., Lundin, C., Hodgson, B., and Sharma, R. A. (2008). DNA repair pathways as targets for cancer therapy. Nat. Rev. Cancer 8, 193-204. doi: $10.1038 / \mathrm{nrc} 2342$

Hickman, A. W., Jaramillo, R. J., Lechner, J. F., and Johnson, N. F. (1994). Alphaparticle-induced p53 protein expression in a rat lung epithelial cell strain. Cancer Res. 54, 5797-5800.
Hickson, I., Zhao, Y., Richardson, C. J., Green, S. J., Martin, N. M. B., Orr, A. I., et al. (2004). Identification and characterization of a novel and specific inhibitor of the ataxia-telangiectasia mutated kinase ATM. Cancer Res. 64, 9152-9159. doi: 10.1158/0008-5472.CAN-04-2727

Huang, S. M., and Harari, P. M. (2000). Modulation of radiation response after epidermal growth factor receptor blockade in squamous cell carcinomas: inhibition of damage repair, cell cycle kinetics, and tumor angiogenesis. Clin. Cancer Res. 6, 2166-2174.

International Agency for Research on Cancer (IARC). (2010). GLOBOCAN 2008, Cancer Incidence and Mortality Worldwide. Lyon: International Agency for Research on Cancer.

Ivanov, V. N., Zhou, H., Ghandhi, S. A., Karasic, T. B., Yaghoubian, B., Amundson, S. A., et al. (2010). Radiation-induced bystander signaling pathways in human fibroblasts: a role for interleukin-33 in the signal transmission. Cell. Signal. 22, 1076-1087. doi: 10.1016/j.cellsig.2010.02.010

Iyer, R., Lehnert, B. E., and Svensson, R. (2000). Factors underlying the cell growthrelated bystander responses to alpha particles. Cancer Res. 60, 1290-1298.

Jacinto, E., and Hall, M. N. (2003). Tor signalling in bugs, brain and brawn. Nat. Rev. Mol. Cell. Biol. 4, 117-126. doi: 10.1038/nrm1018

Jemal, A., Center, M. M., DeSantis, C., and Ward, E. M. (2010). Global patterns of cancer incidence and mortality rates and trends. Cancer Epidemiol. Biomarkers. Prev. 19, 1893-1907. doi: 10.1158/1055-9965.EPI-10-0437

Jiang, Y., Chen, X., Tian, W., Yin, X., Wang, J., and Yang, H. (2014). The role of TGF- $\beta 1$-miR-21-ROS pathway in bystander responses induced by irradiated non-small-cell lung cancer cells. Br. J. Cancer 111, 772-780. doi: 10.1038/bjc. 2014.368

Jorgensen, T. J. (2009). Enhancing radiosensitivity: targeting the DNA repair pathways. Cancer Biol. Ther. 8, 665-670. doi: 10.4161/cbt.8.8.8304

Karrison, T. G., Ferguson, D. J., and Meier, P. (1999). Dormancy of mammary carcinoma after mastectomy. J. Natl. Cancer Inst. 91, 80-85. doi: 10.1093/jnci/91.1.80

Klammer, H., Mladenov, E., Li, F., and Iliakis, G. (2013). Bystander effects as manifestation of intercellular communication of DNA damage and of the cellular oxidative status. Cancer Lett. doi: 10.1016/j.canlet.2013.12.017. [Epub ahead of print].

Koturbash, I., Boyko, A., Rodriguez-Juarez, R., McDonald, R. J., Tryndyak, V. P., Kovalchuk, I., et al. (2007). Role of epigenetic effectors in maintenance of the long-term persistent bystander effect in spleen in vivo. Carcinogenesis 28 , 1831-1838. doi: 10.1093/carcin/bgm053

Kuwahara, Y., Mori, M., Kitahara, S., Fukumoto, M., Ezaki, T., Mori, S., et al. (2014). Targeting of tumor endothelial cells combining 2 Gy/day of X-ray with Everolimus is the effective modality for overcoming clinically relevant radioresistant tumors. Cancer Med. 3, 310-321. doi: 10.1002/cam4.185

Lai, P. B. S., Chi, T.-Y., and Chen, G. G. (2007). Different levels of p53 induced either apoptosis or cell cycle arrest in a doxycycline-regulated hepatocellular carcinoma cell line in vitro. Apoptosis 12, 387-393. doi: 10.1007/s10495-0060571-1

Lawrence, T. S., Ten Haken, R. K., and Giaccia, A. (2008). "Principles of radiation oncology," in Cancer: Principles and Practice of Oncology, 8th Edn., Chapter 21, eds V. T. DeVita Jr., T. S. Lawrence, and S. A. Rosenberg (Philadelphia, PA: Lippincott Williams and Wilkins).

Liauw, S. L., Connell, P. P., and Weichselbaum, R. R. (2013). New paradigms and future challenges in radiation oncology: an update of biological targets and technology. Sci. Transl. Med. 5, 173sr2. doi: 10.1126/scitranslmed.30 05148

Liu, L., Zhu, X.-D., Wang, W.-Q., Shen, Y., Qin, Y., Ren, Z.-G., et al. (2010). Activation of beta-catenin by hypoxia in hepatocellular carcinoma contributes to enhanced metastatic potential and poor prognosis. Clin. Cancer Res. 16, 2740-2750. doi: 10.1158/1078-0432.CCR-09-2610

Loeffler, J. S., and Durante, M. (2013). Charged particle therapy-optimization, challenges and future directions. Nat. Rev. Clin. Oncol. 10, 411-424. doi: 10.1038/nrclinonc.2013.79

Lyng, F. M., Seymour, C. B., and Mothersill, C. (2002). Early events in the apoptotic cascade initiated in cells treated with medium from the progeny of irradiated cells. Radiat. Prot. Dosimetry 99, 169-172. doi: 10.1093/oxfordjournals.rpd.a006753

Martin, O. A., Anderson, R. L., Russell, P. A., Cox, R. A., Ivashkevich, A., Swierczak, A., et al. (2014). Mobilization of viable tumor cells into the circulation during radiation therapy. Int. J. Radiat. Oncol. Biol. Phys. 88, 395-403. doi: 10.1016/j.ijrobp.2013.10.033 
McGale, P., Taylor, C., Correa, C., Cutter, D., Duane, F., Ewertz, M., et al. (2014). Effect of radiotherapy after mastectomy and axillary surgery on 10-year recurrence and 20-year breast cancer mortality: meta-analysis of individual patient data for 8135 women in 22 randomised trials. Lancet 383, 2127-2135. doi: 10.1016/S0140-6736(14)60488-8

Moding, E. J., Kastan, M. B., and Kirsch, D. G. (2013). Strategies for optimizing the response of cancer and normal tissues to radiation. Nat. Rev. Drug Discov. 12, 526-542. doi: 10.1038/nrd4003

Mohseni-Meybodi, A., Mozdarani, H., and Mozdarani, S. (2009). DNA damage and repair of leukocytes from Fanconi anaemia patients, carriers and healthy individuals as measured by the alkaline comet assay. Mutagenesis 24, 67-73. doi: 10.1093/mutage/gen052

Mothersill, C., and Seymour, C. B. (1998). Mechanisms and implications of genomic instability and other delayed effects of ionizing radiation exposure. Mutagenesis 13, 421-426. doi: 10.1093/mutage/13.5.421

Mothersill, C., Seymour, R. J., and Seymour, C. B. (2006). Increased radiosensitivity in cells of two human cell lines treated with bystander medium from irradiated repair-deficient cells. Radiat. Res. 165, 26-34. doi: 10.1667/RR3488.1

Munro, A. J. (2009). Bystander effects and their implications for clinical radiotherapy. J. Radiol. Prot. 29, A133-A142. doi: 10.1088/0952-4746/29/2A/S09

Nagasawa, H., and Little, J. B. (1992). Induction of sister chromatid exchanges by extremely low doses of alpha-particles. Cancer Res. 52, 6394-6396.

Niemantsverdriet, M., van Goethem, M.-J., Bron, R., Hogewerf, W., Brandenburg, S., Langendijk, J. A., et al. (2012). High and low LET radiation differentially induce normal tissue damage signals. Int. J. Radiat. Oncol. Biol. Phys. 83, 1291-1297. doi: 10.1016/j.ijrobp.2011.09.057

Núñez, M. I., McMillan, T. J., Valenzuela, M. T., Ruiz de Almodóvar, J. M., and Pedraza, V. (1996). Relationship between DNA damage, rejoining and cell killing by radiation in mammalian cells. Radiother. Oncol. 39, 155-165.

Nyati, M. K., Morgan, M. A., Feng, F. Y., and Lawrence, T. S. (2006). Integration of EGFR inhibitors with radiochemotherapy. Nat. Rev. Cancer 6, 876-885. doi: 10.1038/nrc1953

Parshad, R., Sanford, K. K., and Jones, G. M. (1993). Chromatid damage after G2 phase x-irradiation of cells from cancer-prone individuals implicates deficiency in DNA repair. Proc. Natl. Acad. Sci. U.S.A. 80, 5612-5616. doi: 10.1073/pnas.80.18.5612

Pfitzenmaier, J., Ellis, W. J., Arfman, E. W., Hawley, S., McLaughlin, P. O., Lange, P. H., et al. (2006). Telomerase activity in disseminated prostate cancer cells. BJU Int. 97, 1309-1313. doi: 10.1111/j.1464-410X.2006.06194.x

Ponnaiya, B., Cornforth, M. N., and Ullrich, R. L., (1997). Induction of chromosomal instability in human mammary cells by neutrons and gamma rays. Radiat. Res. 147, 288-294. doi: 10.2307/3579335

Ponnaiya, B., Jenkins-Baker, G., Bigelow, A., Marino, S., and Geard, C. R. (2004). Detection of chromosomal instability in alpha-irradiated and bystander human fibroblasts. Mutat. Res. 568, 41-48. doi: 10.1016/j.mrfmmm.2004.06.045

Prise, K. M. (2006). New advances in radiation biology. Occup. Med. (Lond.) 56, 156-161. doi: 10.1093/occmed/kql010

Rainey, M. D., Charlton, M. E., Stanton, R. V., and Kastan, M. B. (2008). Transient inhibition of ATM kinase is sufficient to enhance cellular sensitivity to ionizing radiation. Cancer Res. 68, 7466-7474. doi: 10.1158/0008-5472.CAN08-0763

Ringborg, U., Bergqvist, D., Brorsson, B., Cavallin-Ståhl, E., Ceberg, J., Einhorn, N., et al. (2003). The Swedish Council on Technology Assessment in Health Care (SBU) systematic overview of radiotherapy for cancer including a prospective survey of radiotherapy practice in Sweden 2001-summary and conclusions. Acta. Oncol. 42, 357-365. doi: 10.1080/02841860310010826

Rodemann, H. P., Dittmann, K., and Toulany, M. (2007). Radiation-induced EGFRsignaling and control of DNA-damage repair. Int. J. Radiat. Biol. 83, 781-791. doi: 10.1080/09553000701769970

Rodemann, H. P., and Blaese, M. A. (2007). Responses of normal cells to ionizing radiation. Semin. Radiat. Oncol. 17, 81-88. doi: 10.1016/j.semradonc.2006.11.005

Sabatini, D. M. (2006). mTOR and cancer: insights into a complex relationship. Nat. Rev. Cancer 6, 729-734. doi: 10.1038/nrc1974

Sawant, S. G., Randers-Pehrson, G., Geard, C. R., Brenner, D. J., and Hall, E. J. (2001). The bystander effect in radiation oncogenesis: I. Transformation in $\mathrm{C} 3 \mathrm{H} 10 \mathrm{~T} 1 / 2$ cells in vitro can be initiated in the unirradiated neighbors of irradiated cells. Radiat. Res. 155, 397-401. doi: 10.1667/00337587(2001)155[0397:TBEIRO]2.0.CO;2
Seymour, C. B., and Mothersill, C. (1997). Delayed expression of lethal mutations and genomic instability in the progeny of human epithelial cells that survived in a bystander-killing environment. Radiat. Oncol. Investig. 5, 106-110.

Seiwert, T. Y., Salama, J. K., and Vokes, E. E. (2007). The chemoradiation paradigm in head and neck cancer. Nat. Clin. Pract. Oncol. 4, 156-171. doi: 10.1038/ncponc0750

Shahidi, M., Mozdarani, H., and Bryant, P. E. (2007). Radiation sensitivity of leukocytes from healthy individuals and breast cancer patients as measured by the alkaline and neutral comet assay. Cancer Lett. 257, 263-273. doi: 10.1016/j.canlet.2007.08.002

Shahidi, M., Mozdarani, H., and Mueller, W.-U. (2010). Radiosensitivity and repair kinetics of gamma-irradiated leukocytes from sporadic prostate cancer patients and healthy individuals assessed by alkaline comet assay. Iran Biomed. J. 14, 67-75.

Shao, C., Furusawa, Y., Aoki, M., Matsumoto, H., and Ando, K. (2002). Nitric oxide-mediated bystander effect induced by heavy-ions in human salivary gland tumour cells. Int. J. Radiat. Biol. 78, 837-844. doi: 10.1080/095530002101 49786

Shao, C., Furusawa, Y., Kobayashi, Y., Funayama, T., and Wada, S. (2003). Bystander effect induced by counted high-LET particles in confluent human fibroblasts: a mechanistic study. FASEB J. 17, 1422-1427. doi: 10.1096/fj.02-11 $15 \mathrm{com}$

Shao, C., Folkard, M., Michael, B. D., and Prise, K. M. (2004). Targeted cytoplasmic irradiation induces bystander responses. Proc. Natl. Acad. Sci. U.S.A. 101, 13495-13500. doi: 10.1073/pnas.0404930101

Shareef, M. M., Cui, N., Burikhanov, R., Gupta, S., Satishkumar, S., Shajahan, S., et al. (2007). Role of tumor necrosis factor-alpha and TRAIL in high-dose radiation-induced bystander signaling in lung adenocarcinoma. Cancer Res. 67, 11811-11820. doi: 10.1158/0008-5472.CAN-07-0722

Shen, C., Oswald, D., Phelps, D., Cam, H., Pelloski, C. E., Pang, Q., et al. (2013). Regulation of FANCD2 by the mTOR pathway contributes to the resistance of cancer cells to DNA double-strand breaks. Cancer Res. 73, 3393-3401. doi: 10.1158/0008-5472.CAN-12-4282

Siegel, R., Naishadham, D., and Jemal, A. (2012). Cancer statistics. CA Cancer J. Clin. 62, 10-29. doi: 10.3322/caac.20138

Sokolov, M. V., Dickey, J. S., Bonner, W. M., and Sedelnikova, O. A. (2007). gamma$\mathrm{H} 2 \mathrm{AX}$ in bystander cells: not just a radiation-triggered event, a cellular response to stress mediated by intercellular communication. Cell Cycle 6, 2210-2212. doi: 10.4161/cc.6.18.4682

Sokolov, M. V., and Neumann, R. D. (2010). Radiation-induced bystander effects in cultured human stem cells. PLoS ONE 5:e14195. doi: 10.1371/journal.pone.0014195

Stiewe, T. (2007). The p53 family in differentiation and tumorigenesis. Nat. Rev. Cancer 7, 165-168. doi: 10.1038/nrc2072

Sudo, H., Garbe, J., Stampfer, M. R., Barcellos-Hoff, M. H., and Kronenberg, A. (2008). Karyotypic instability and centrosome aberrations in the progeny of finite life-span human mammary epithelial cells exposed to sparsely or densely ionizing radiation. Radiat. Res. 170, 23-32. doi: 10.1667/RR1317.1

Suzuki, K., Ojima, M., Kodama, S., and Watanabe, M. (2003). Radiationinduced DNA damage and delayed induced genomic instability. Oncogene 22, 6988-6993. doi: 10.1038/sj.onc.1206881

Suzuki, K., and Yamashita, S. (2014). Radiation-induced bystander response: mechanism and clinical implications. Adv. Wound Care 3, 16-24. doi: 10.1089/wound.2013.0468

Temme, J., and Bauer, G. (2013). Low-dose gamma irradiation enhances superoxide anion production by nonirradiated cells through TGF- $\beta 1$-dependent bystander signaling. Radiat. Res. 179, 422-432. doi: 10.1667/RR3161.2

Thariat, J., Hannoun-Levi, J.-M., Sun Myint, A., Vuong, T., and Gérard, J.-P. (2013). Past, present, and future of radiotherapy for the benefit of patients. Nat. Rev. Clin. Oncol. 10, 52-60. doi: 10.1038/nrclinonc.2012.203

Thun, M. J., DeLancey, J. O., Center, M. M., Jemal, A., and Ward, E. M. (2010). The global burden of cancer: priorities for prevention. Carcinogenesis 31, 100-110. doi: $10.1093 /$ carcin/bgp263

Toulany, M., and Rodemann, H. P. (2013). Potential of Akt mediated DNA repair in radioresistance of solid tumors over expressing erbB-PI3K-Akt pathway. Transl. Cancer Res. 2, 190-202.

Veldwijk, M. R., Zhang, B., Wenz, F., and Herskind, C. (2014). The biological effect of large single doses: a possible role for non-targeted effects in cell inactivation. PLoS ONE 9:e84991. doi: 10.1371/journal.pone.0084991 
Veuger, S. J., Curtin, N. J., Richardson, C. J., Smith, G. C. M., and Durkacz, B. W. (2003). Radiosensitization and DNA repair inhibition by the combined use of novel inhibitors of DNA-dependent protein kinase and poly(ADP-ribose) polymerase-1. Cancer Res. 63, 6008-6015.

Wang, Z., Huang, Y., and Zhang, J. (2014). Molecularly targeting the PI3K-AktmTOR pathway can sensitize cancer cells to radiotherapy and chemotherapy. Cell. Mol. Biol. Lett. 19, 233-242. doi: 10.2478/s11658-014-0191-7

Weckermann, D., Müller, P., Wawroschek, F., Harzmann, R., Riethmüller, G., and Schlimok, G. (2001). Disseminated cytokeratin positive tumor cells in the bone marrow of patients with prostate cancer: detection and prognostic value. J. Urol. 166, 699-703. doi: 10.1016/S0022-5347(05)66046-6

Wullschleger, S., Loewith, R., and Hall, M. N. (2006). TOR signaling in growth and metabolism. Cell 124, 471-484. doi: 10.1016/j.cell.2006.01.016

Zhou, H., Randers-Pehrson, G., Waldren, C. A., Vannais, D., Hall, E. J., and Hei, T. K. (2000). Induction of a bystander mutagenic effect of alpha particles in mammalian cells. Proc. Natl. Acad. Sci. U.S.A. 97, 2099-2104. doi: 10.1073/pnas.030420797
Conflict of Interest Statement: The authors declare that the research was conducted in the absence of any commercial or financial relationships that could be construed as a potential conflict of interest.

Received: 11 July 2014; accepted: 31 October 2014; published online: 17 November 2014.

Citation: Baskar R, Dai J, Wenlong N, Yeo R and Yeoh K-W (2014) Biological response of cancer cells to radiation treatment. Front. Mol. Biosci. 1:24. doi: 10.3389/fmolb. 2014.00024

This article was submitted to Cellular Biochemistry, a section of the journal Frontiers in Molecular Biosciences.

Copyright (c) 2014 Baskar, Dai, Wenlong, Yeo and Yeoh. This is an open-access article distributed under the terms of the Creative Commons Attribution License (CC BY).

The use, distribution or reproduction in other forums is permitted, provided the original author(s) or licensor are credited and that the original publication in this journal is cited, in accordance with accepted academic practice. No use, distribution or reproduction is permitted which does not comply with these terms. 